\title{
Burden of Misconception in Sexual Health Care Setting: A Cross-Sectional Investigation among the Patients Attending a Psychiatric Sex Clinic of Bangladesh
}

\author{
S. M. Yasir Arafat and Srijony Ahmed \\ Department of Psychiatry, Bangabandhu Sheikh Mujib Medical University, Dhaka, Bangladesh \\ Correspondence should be addressed to S. M. Yasir Arafat; arafatdmc62@gmail.com
}

Received 6 April 2017; Revised 16 May 2017; Accepted 24 May 2017; Published 27 June 2017

Academic Editor: Umberto Albert

Copyright ( 2017 S. M. Yasir Arafat and Srijony Ahmed. This is an open access article distributed under the Creative Commons Attribution License, which permits unrestricted use, distribution, and reproduction in any medium, provided the original work is properly cited.

\begin{abstract}
Background. Bangladesh is a country in South Asia with about 160 million people and achieved health related Millennium Development Goals (MDG) significantly. But sexual health is still an untapped issue with predominant myths and misconception. Objective. We aimed to look into the proportions of patients attending sexual health care services due to misconceptions. Methods. The descriptive, cross-sectional study was conducted among 110 patients attending Psychiatric Sex Clinic (PSC) of Bangabandhu Sheikh Mujib Medical University. Respondents were included in the study with convenient sampling from November 2016 to March 2017. Data were collected through face-to-face interview with semistructured preformed, pretested questionnaire and analyzed by SPSS software 16.0 version. Results. Most of the patients (93\%) were male, $60 \%$ were married, $62 \%$ were urban habitant, $42 \%$ were under grade 10 , and $33 \%$ were service holder. Total $55 \%$ of the patients had misconceptions and $29 \%$ visited only for misconception; $14 \%$ had Premature Ejaculation; and 12\% had desire disorder. $32 \%$ of the patients had psychiatric disorders and among them depression was most common, 13\%. Conclusion. Positive openness in sexual health and appropriate strategy should be taken to improve the quality of sexual life as well as reduce the misconception in the people of Bangladesh.
\end{abstract}

\section{Introduction}

World Health Organization (WHO) defines sexual health as "a state of physical, emotional, mental, and social wellbeing in relationship to sexuality; it is not merely the absence of disease, dysfunction, or infirmity [1-3]." Positive sexual health requires respectful approach to sexuality with possibility of having pleasurable and safe sexual experiences with those who are free of coercion, discrimination, and violence $[1,2]$. Sexuality, partner role, distribution of dysfunctions, perception, and expression of sexual complaints often vary in the aspects of different cultures, societies, countries, religions, and other such aspects. Dysfunctions may prevail globally but expression, presentation, help seeking behavior, and approaches to correct the dysfunctions often vary. Bangladesh is a developing country in South Asia with about 160 million people and achieved health related Millennium
Development Goals (MDG) significantly [4]. The literacy rate is increasing day by day and currently $61.0 \%$ of the population have 15 years and above age group education year [4]. But the health literacy state is still in dearth in Bangladesh and misconceptions direct the population to pursue abnormal health seeking behaviors $[2,5]$. Sexuality is still a covert issue in Bangladesh and people usually hesitate to start talk regarding sex $[3,5]$. Traditional healers and vaids contribute to disseminating different sexual misconception in addition to the existing cultural and religious myths [5, 6]. There is dearth of research as well as publications to assess the local misconception and to remove the myths. In addition there is no specialized services center to deal with sexual dysfunctions [3]. So, sufferers are in grave situation as they find difficulties to reach the appropriate services provider and to get relief from the problem. Authors aimed to look into the proportions of patients attended for sexual 
health care services due to misconceptions in a tertiary care university hospital of Bangladesh. It was also aimed to look into the distribution of misconceptions in relation to the demographic variables.

\section{Methods}

2.1. Place of the Study. Bangabandhu Sheikh Mujib Medical University (BSMMU) is the only medical university for about 160 million population of Bangladesh to date. Also, Psychiatric Sex Clinic (PSC) is the single specialized psychiatric service based sex clinic in the country. The clinic is run under the Department of Psychiatry, BSMMU, headed by an associate professor of psychiatry. Only referred patients are serviced here and there is allocated time to attend the clinic in a single day of the week. The usual turnover is about 15-20 patients per session of the clinic. In Bangladesh the patients with sexual complaints usually visit Dermatology and Venereology Department and the referral system is not well defined yet. Most of the referrals are from the Psychiatry Outpatient Department (OPD), and due to regular activity and awareness programs there are few referrals from other disciplines such as Dermatology \& Venereology Department.

2.2. Methods. The descriptive, cross-sectional observational study was conducted among 110 patients attending PSC of BSMMU. Respondents were chosen with convenient purposive sampling within the period of November 2016 to March 2017. Data were collected through face-to-face interview with semistructured preformed, pretested questionnaire by the authors themselves and analyzed by SPSS 16.0 software.

2.3. Questionnaire. A semistructured questionnaire was formed to conduct the study. In demographic part age, sex, residence, nuptial status, educational status, occupation, source of referral, and history of substance abuse were included. And chief complaints, duration of illness, psychiatric comorbidity, cooccurring medical history, and other notable findings of clinical interview were included in the diseases part.

\section{Results}

The mean age of the respondents was $30.42 \pm 8.13$ years (mean $\pm \mathrm{SD})$ and range was $17-55$ years. Majority of the patients (52\%) belonged to $26-35$-year group. $93 \%$ of the respondents were male, $60 \%$ were married, $63 \%$ were urban habitant, $42 \%$ studied less than grade 10 (S.S.C.), and 34\% belonged to service holder as an occupational class (Table 1).

Among the respondents $60(54.44 \%)$ patients had misconceptions (MC) regarding sexual health, function, illness, and disorders as well as treatments. $29 \%$ of the patients visited for the problems only related to misconceptions and others visited for misconception along with sexual dysfunctions comorbidly (Table 2). Among the sexual dysfunctions Premature Ejaculation was most common (13.64\%) in males and among the female sexual dysfunctions, Female Sexual Arousal/Interest Disorder (FSAID) was the most common
TABLE 1: Distribution of demographic variables of the respondents $(n=110)$.

\begin{tabular}{|c|c|c|}
\hline Demographic variable & Frequency & Percentage \\
\hline \multicolumn{3}{|l|}{ Age in years } \\
\hline $17-25$ & 34 & 30.91 \\
\hline $26-35$ & 57 & 51.82 \\
\hline $36-45$ & 11 & 10.00 \\
\hline $46-55$ & 8 & 7.27 \\
\hline \multicolumn{3}{|l|}{ Sex } \\
\hline Male & 102 & 92.73 \\
\hline Female & 8 & 7.27 \\
\hline \multicolumn{3}{|l|}{ Marital status } \\
\hline Single & 40 & 36.36 \\
\hline Married & 66 & 60.00 \\
\hline Separated & 1 & 0.91 \\
\hline Divorced & 3 & 2.73 \\
\hline \multicolumn{3}{|l|}{ Habitat } \\
\hline Urban & 69 & 62.73 \\
\hline Rural & 41 & 37.27 \\
\hline \multicolumn{3}{|l|}{ Education } \\
\hline Under S.S.C. & 46 & 41.82 \\
\hline S.S.C. completed & 12 & 10.91 \\
\hline H.S.C. completed & 23 & 20.91 \\
\hline Honors & 16 & 14.55 \\
\hline Masters & 13 & 11.82 \\
\hline \multicolumn{3}{|l|}{ Occupation } \\
\hline Farmer & 4 & 5.41 \\
\hline Service holder & 25 & 33.78 \\
\hline Professionals & 6 & 8.11 \\
\hline Unemployed & 5 & 6.76 \\
\hline Businessman & 10 & 13.51 \\
\hline Student & 12 & 16.22 \\
\hline Housewife & 6 & 8.11 \\
\hline Abroad & 1 & 1.35 \\
\hline Day laborer & 5 & 6.76 \\
\hline
\end{tabular}

(7.27\%) (Table 2). All the female respondents were found to have FSAID. This finding can be explained by the cultural pattern of the females in Bangladesh where females consider sex as a minor consideration. Few patients presented with global dysfunctions along with misconception (Table 2).

Among the psychiatric disorders the most common diagnosis was Major Depressive Disorder (MDD) (13.64\%) and among the general medical condition infertility was found as an important diagnosis (5.45\%) (Table 3). Among the respondents $9(8.18 \%)$ patients presented with the history of substances abuse (Table 3 ). The result revealed that misconception prevailed in the younger age as $91 \%$ of the patients with misconceptions were under 35 years and majority were in the 26-35-year group (50\%) (Figure 1). Exploration of misconception with educational qualification revealed that misconception was also found in the well educated persons and even in masters holders (11.67\%) but it was found the most in under S.S.C. (under grade 10) education group (36.67\%) (Figure 2). But the ratio of misconception in educational qualification to the total sample educational qualification is nearly the same (Table 1 and Figure 2). 
TABLE 2: Distribution of problems among the respondents $(n=$ 110).

\begin{tabular}{lcc}
\hline Problems of the patients & Frequency & Percent \\
\hline Misconception (MC) & 32 & 29.09 \\
Premature Ejaculation (PE) & 15 & 13.64 \\
MC + PE & 13 & 11.82 \\
Erectile Dysfunction (ED) & 9 & 8.18 \\
MC + ED & 9 & 8.18 \\
Female Sexual Arousal/Interest & 8 & 7.27 \\
Disorder (FSAID) & 6 & \\
PE + ED & 6.45 \\
Hypoactive Sexual Desire Disorder & 5 & 4.55 \\
(HSDD) & 3 & 2.73 \\
Homosexuality & 2 & 1.82 \\
MC + PE + HSDD + ED & 2 & 1.82 \\
MC + PE + ED & 2 & 1.82 \\
Orgasmic disorder & 2 & 1.82 \\
MC + homosexuality & 2 & 1.82 \\
HSDD + ED & 110 & 100 \\
Total & & \\
\hline
\end{tabular}

TABLE 3: Distribution of comorbid disorders among the respondents $(n=110)$.

\begin{tabular}{|c|c|c|}
\hline Psychiatric disorders & Frequency & Percent \\
\hline MDD & 15 & 13.64 \\
\hline Schizophrenia & 4 & 3.64 \\
\hline GAD & 3 & 2.73 \\
\hline Personality disorder & 2 & 1.82 \\
\hline OCD & 2 & 1.82 \\
\hline Social phobia & 2 & 1.82 \\
\hline Bipolar 1 & 2 & 1.82 \\
\hline Gender identity disorder & 1 & 0.91 \\
\hline Delusional disorder & 1 & 0.91 \\
\hline Panic disorder & 1 & 0.91 \\
\hline Somatic symptom Disorder & 1 & 0.91 \\
\hline Total & 34 & 30.91 \\
\hline Other disorders & Frequency & Percent \\
\hline Infertility & 6 & 5.45 \\
\hline HTN & 3 & 2.73 \\
\hline IBS & 3 & 2.73 \\
\hline Hypothyroidism & 2 & 1.82 \\
\hline $\mathrm{DM}$ & 1 & 0.91 \\
\hline Epilepsy & 1 & 0.91 \\
\hline Thyrotoxicosis & 1 & 0.91 \\
\hline Total & 17 & 15.45 \\
\hline Substance & Frequency & Percent \\
\hline Yes & 9 & 8.18 \\
\hline No & 101 & 91.82 \\
\hline Total & 110 & 100 \\
\hline
\end{tabular}

MDD: Major Depressive Disorder; GAD: Generalized Anxiety Disorder; OCD: Obsessive Compulsive Disorder; HTN: hypertension; IBS: irritable bowel syndrome; DM: diabetes mellitus.

\section{Discussion}

It was aimed at seeing the burden of misconception in terms of proportion of patients attending a Psychiatric Sex

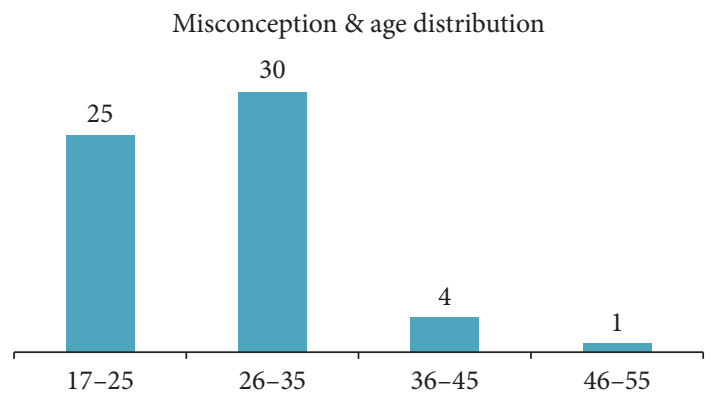

(Y)

FIGURE 1: Distribution of misconception with age among respondents $(n=60)$.

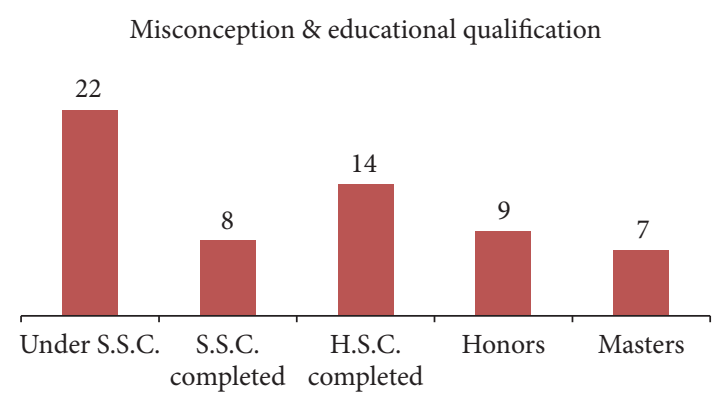

FIGURE 2: Distribution of misconception with educational qualification among the respondents $(n=60)$.

Clinic in Bangladesh because based on clinical observation authors thought misconceptions might be a major cause of sexual service consumption. The result revealed that majority $(82.73 \%)$ of respondents were below the 35 -year age group; more than half of the study population had study less than S.S.C. (Under grade 10), and 36.36\% were unmarried (Table 1). Young unmarried less educated people are visiting more and misconception was found to be the major cause for visiting and these results are aligned with similar article in neighboring country as well as few reported articles in the same country regarding misconceptions [58]. The results revealed that total of about $55 \%$ patients visited for their problems along with sexual misconception and about $29 \%$ patients visited for their problem caused only for their misconception (Tables 2 and 3). Previous available studies and articles revealed similar pattern of presentation and services consumptions [6-8]. Arafat SMY mentioned Dhat syndrome is a frequently presented but underaddressed misconception in the primary care level of Bangladesh and the syndromal presentation is well recognized in this culture [6-8]. Depression was found as most common psychiatric comorbidity and the result can be explained by the pathophysiology and symptom presentation of depression $[9,10]$. The distribution of misconception was found more in the younger age (Figure 1) and that is supported by previous literature of Dhat syndromes and/or cultural bound syndrome [6-8]. Dhat syndrome is a culture bound syndrome of the Indian subcontinent which is characterized by preoccupation with loss of "Dhat" (semen) and attribution of different 
physical and psychological symptoms [6-8]. Dhat syndrome is placed in the classificatory system (DSM-IV and ICD-10) earlier, but in DSM 5 it is placed in the glossary section $[6,11-13]$. Interestingly attitude to the misconceptions was not found to be changed with educational achievements among the study population. It was prevalent nearly in the same ratio to the total sample with the educational status in all educational groups (Table 1 and Figure 2). This situation could be explained by considering that the study population were the referred clinical samples, not the general population. However, that might be due to lack of systemized and coordinated education regarding sex in the academic curricula. The high prevalence of misconceptions could be explained by cultural covertness regarding sex [3] and lack of poor health literacy in curricula [4] and samples were taken from clinical populations, single centered study, preexisting myths $[5,6]$, religious misperceptions $[3,5]$, and other such factors. Creating awareness regarding sexual health as a part of the holistic health, incorporating sexual health education in school curriculum, preventing the unauthentic dissemination of sexual myths, specialized services center, and proper referral can be considered as further approach in regard to minimizing the services consumptions due to misconception.

\section{Conclusion}

Though larger sample size and multicenter involvement would be better to generalize the results, the study revealed that misconception consumes a major part of resources in a country like Bangladesh. Positive openness in sexual health and appropriate strategies are time demanded to raise the awareness against the myths and misconception as well as raise the overall quality of life of the people of the country.

$\begin{array}{ll}\text { Abbreviations } \\ \text { WHO: } & \text { World Health Organization } \\ \text { MDG: } & \text { Millennium Development Goals } \\ \text { PSC: } & \text { Psychiatric Sex Clinic } \\ \text { BSMMU: } & \text { Bangabandhu Sheikh Mujib Medical } \\ & \text { University } \\ \text { OPD: } & \text { Psychiatry Outpatient Department } \\ \text { MDD: } & \text { Major Depressive Disorder } \\ \text { GAD: } & \text { Generalized Anxiety Disorder } \\ \text { OCD: } & \text { Obsessive Compulsive Disorder } \\ \text { ICD: } & \text { International Statistical Classification of } \\ & \text { Diseases } \\ \text { DSM: } & \text { Diagnostic and Statistical Manual of } \\ & \text { Mental Disorders. }\end{array}$

\section{Conflicts of Interest}

The authors have no conflicts of interest.

\section{Authors' Contributions}

S. M. Yasir Arafat was responsible for conception and design and critical revision of the manuscript, S. M. Yasir Arafat and
Srijony Ahmed were responsible for acquisition of data and for drafting of the manuscript, and all authors approved the manuscript.

\section{Acknowledgments}

The authors thank Dr. Amin Andalib for necessary support during data input.

\section{References}

[1] H. N. Thomas and R. C. Thurston, "A biopsychosocial approach to women's sexual function and dysfunction at midlife: a narrative review," Maturitas, vol. 87, pp. 49-60, 2016.

[2] W. M. Edwards and E. Coleman, "Defining sexual health: a descriptive overview," Archives of Sexual Behavior, vol. 33, no. 3, pp. 189-195, 2004.

[3] M. S. Ahsan, S. M. Y. Arafat, R. Ali, S. M. A. Rahman, S. Ahmed, and M. M. Rahman, "Sexual history taking competency: a survey among the clinicians in Bangladesh," International Journal of Psychiatry, vol. 1, no. 1, article 4, 2016.

[4] M. Saleh Uddin and S. R. Mashrur Ahmed, "Does mind exist in physician's mind? a brief phone survey in Bangladesh," International Journal of Neurorehabilitation, vol. 3, no. 6, article 2, 2016.

[5] S. M. Y. Arafat, "Abnormal health believes with frequent presentations: ethnographic observation from primary care of Bangladesh," International Journal of Perceptions in Public Health, vol. 1, no. 2, pp. 85-86, 2017.

[6] S. M. Y. Arafat, "Dhat syndrome: culture bound, separate entity, or removed," Journal of Behavioral Health, 2017, http://www .jbehavioralhealth.com/?mno=250756.

[7] K. S. Deb and Y. P. S. Balhara, "Dhat syndrome: a review of the world literature," Indian Journal of Psychological Medicine, vol. 35, no. 4, pp. 326-331, 2013.

[8] S. Grover, S. Gupta, and A. Avasthi, "Psychological correlates and psychiatric morbidity in patients with Dhat syndrome," Indian Journal of Psychiatry, vol. 57, no. 3, pp. 255-261, 2015.

[9] P. Cowen, P. Harrison, and T. Burns, Shorter Oxford Textbook of Psychiatry, Oxford University Press, Oxford, UK, 6th edition, 2012.

[10] M. Kermode, H. Herrman, R. Arole, J. White, R. Premkumar, and V. Patel, "Empowerment of women and mental health promotion: a qualitative study in rural Maharashtra, India," BMC Public Health, vol. 7, article 225, 2007.

[11] American Psychiatric Association, Diagnostic and Statistical Manual of Mental Disorders, vol. 1, American Psychiatric Association, Washington, DC, USA, 4th edition, 2000.

[12] World Health Organization, International Statistical Classification of Diseases and Health Related Problems ICD-10, World Health Organization, Geneva, Switzerland, 2nd edition, 2004.

[13] American Psychiatric Association, "Glossary of cultural concepts of distress," in Diagnostic and Statistical Manual of Mental Disorders, pp. 833-839, American Psychiatric Association, Washington, DC, USA, 5th edition, 2013. 


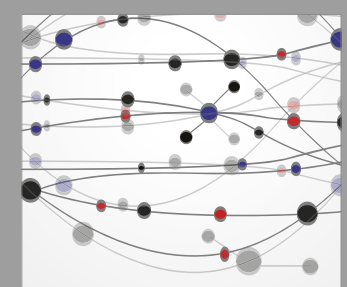

The Scientific World Journal
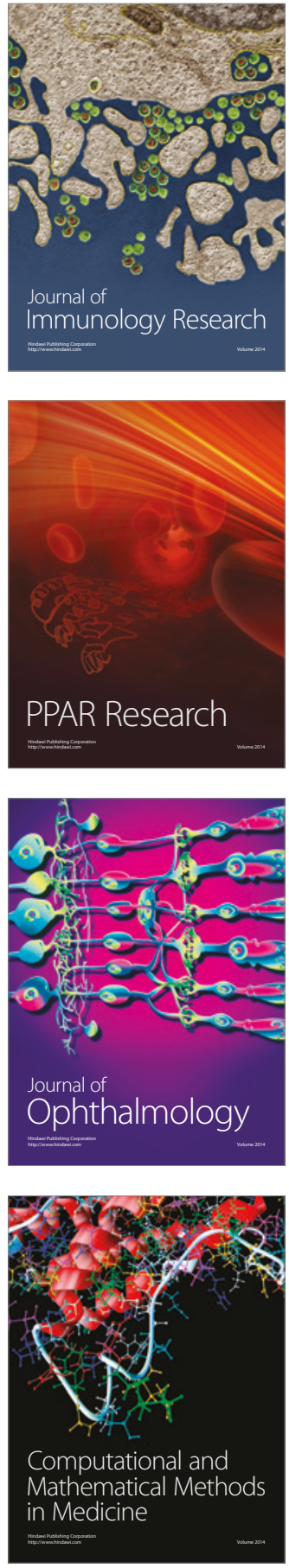

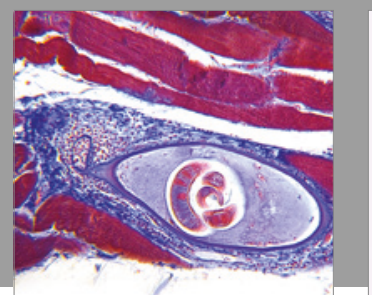

Gastroenterology Research and Practice
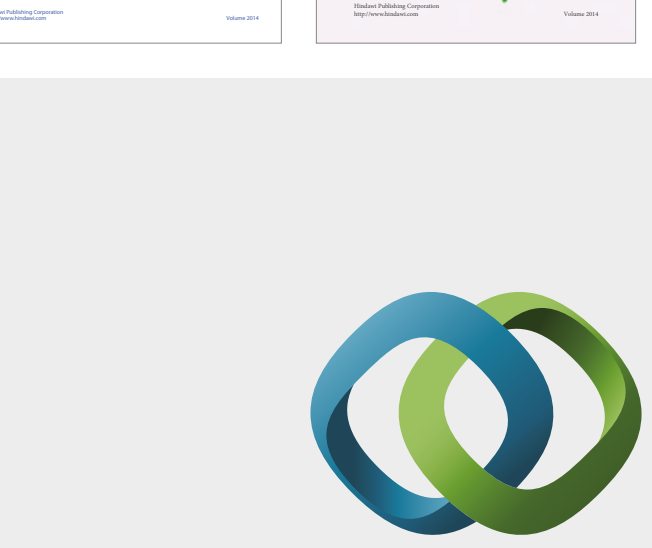

\section{Hindawi}

Submit your manuscripts at

https://www.hindawi.com
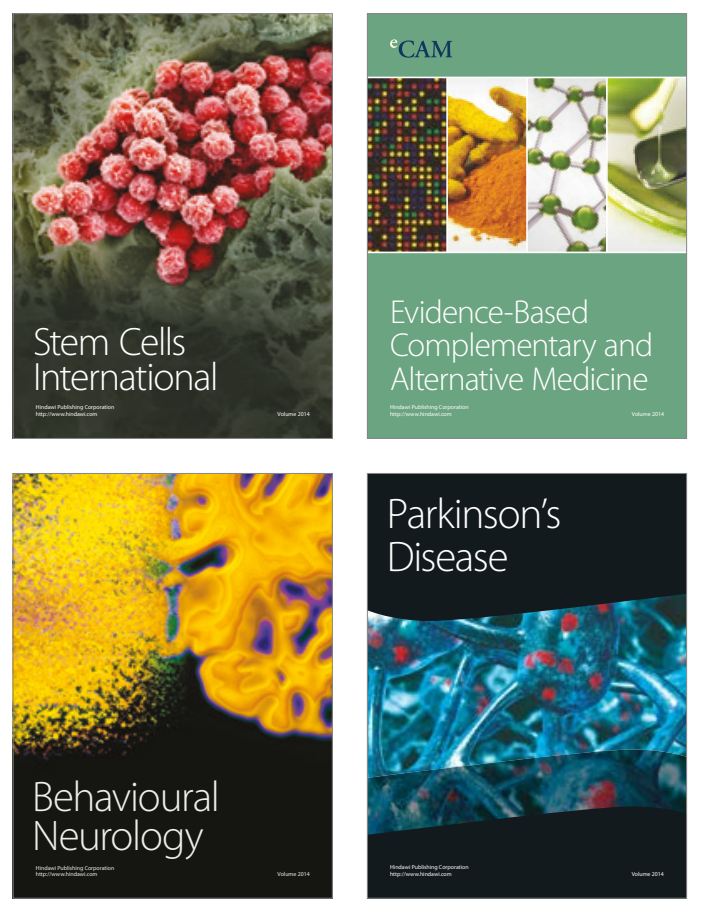
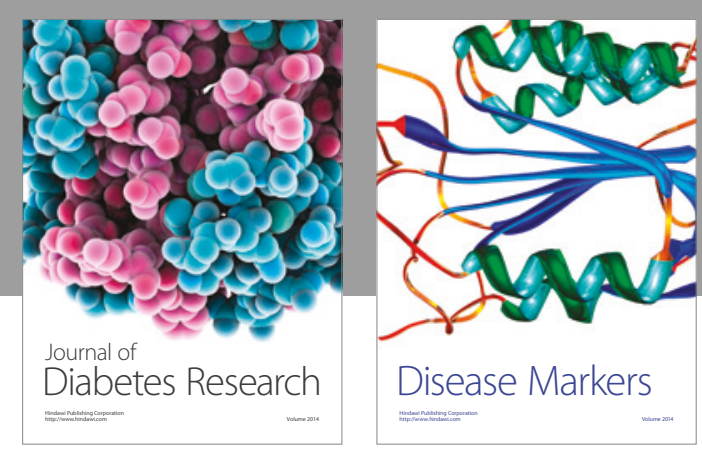

Disease Markers
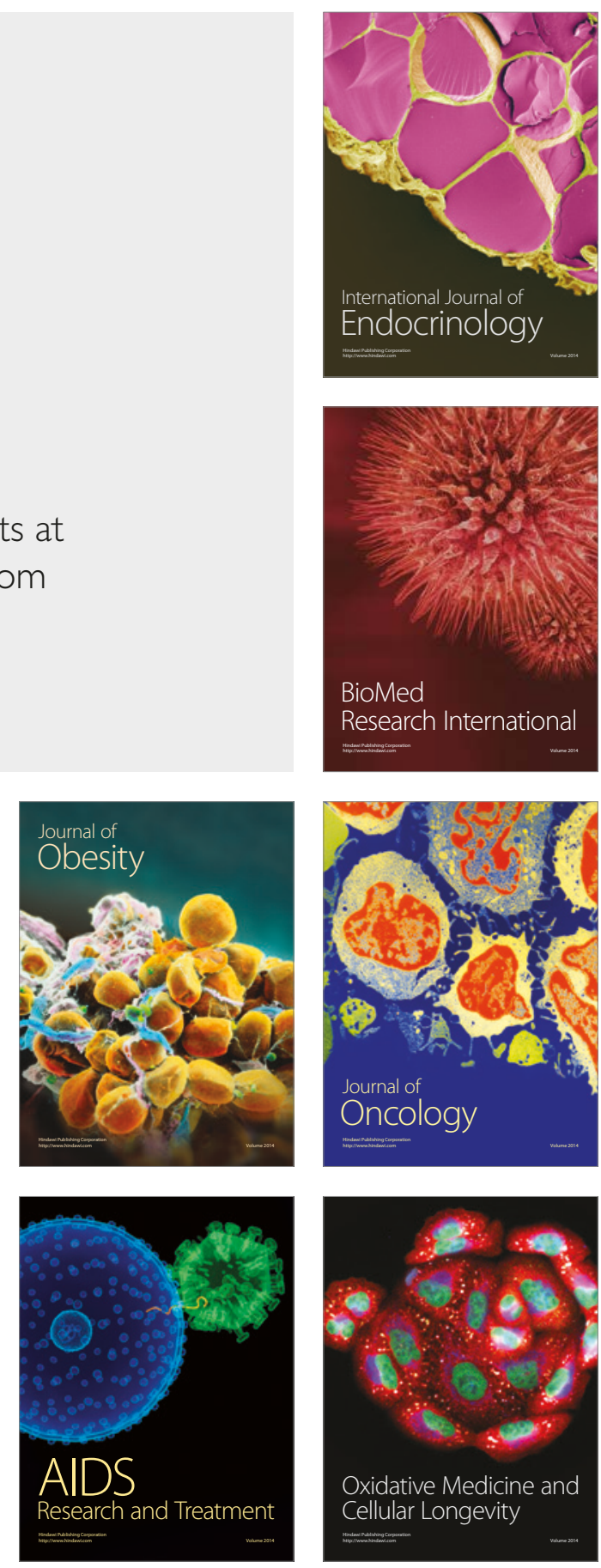